\title{
Futbolistas en Twitter. Una plataforma para la autopromoción
}

\section{Football players on Twitter. A platform for self-promotion}

\author{
Meso Ayerdi, K., Pérez Dasilva, J. A. y Mendiguren Galdospin, T. ${ }^{1}$ \\ Recibido: 30-04-2021 - Aceptado: 05-08-2021 \\ https://doi.org/10.26441/RC20.2-2021-A15
}

RESUMEN: La aparición de las redes sociales ha proporcionado a los futbolistas un medio novedoso y muy eficaz para llegar a sus seguidores e interactuar con ellos. Este nuevo giro en las relaciones entre jugadores y aficionados ha suscitado un reciente debate (Cleland, 2009) sobre los intentos de estos deportistas de conectarse con el público y potenciar sus imágenes de marca a través de Twitter (Hutchins, 2011).

La presente investigación pretende analizar los aspectos del comportamiento en Twitter de los cinco futbolistas que compiten en las principales ligas europeas con mayor número de seguidores en la red de microblogging. Se trata de ver cómo se relacionan estos deportistas con sus aficionados, con quienes hablan y de qué hablan, con el fin de determinar la forma en que estas personas utilizan Twitter para crear marcas personales y forjar conexiones entre ellos y los clubes para los que juegan y los aficionados.

El análisis de contenido se utilizó para detectar los patrones de difusión de los mensajes e identificar a los principales protagonistas de las conversaciones examinadas. También se analizaron las redes semánticas y el uso de hashtag para encontrar correlaciones significativas entre las palabras. Para esta parte del análisis se utilizó NodeXL, programa de software de código abierto más utilizado en el análisis de redes sociales (Hansen, Shneiderman \& Smith, 2010).

Uno de los principales usos que hacen de Twitter está vinculado a la autopromoción. Además, los perfiles de estos futbolistas suelen apoyar iniciativas y campañas solidarias.

Palabras clave: fútbol; Twitter; jugador; fans; conversación; marca, análisis de contenido; NodeXL; autopromoción.

\footnotetext{
${ }^{1}$ Koldobika Meso Ayerdi es Doctor en Periodismo por la Universidad del País Vasco/Euskal Herriko Unibertsitatea y Profesor Titular de Redacción Ciberperiodística, además de la asignatura Bases teóricas y metodología de la investigación en ciberperiodismo en el Master de Investigación Social y de la Comunicación de la misma universidad. Sus principales líneas de investigación son el ciberperiodismo, la innovación educativa y la comunicación corporativa, tal y como lo avalan los diferentes proyectos de investigación que ha dirigido y en los que participa. En la actualidad es director del Departamento de Periodismo. koldo.meso@ehu.eus, http://orcid.org/0000-0002-0400-133X

Jesús Ángel Pérez Dasilva es Doctor en Periodismo por la Universidad del País Vasco/Euskal Herriko Unibertsitatea, en donde imparte la asignatura de Redacción Ciberperiodística. Igualmente, es profesor de la materia Bases teóricas y metodología de la investigación en ciberperiodismo en el Master de Investigación Social y de la Comunicación del que ha sido su máximo responsable. Sus principales líneas de investigación son el ciberperiodismo, los modelos de comunicación y la innovación educativa.. jesusangel.perez@ehu.eus, https://orcid.org/0000-0002-3383-4859

Terese Mendiguren Galdospin es Doctora en Periodismo por la Universidad del País Vasco/Euskal Herriko Unibertsitatea y Profesora de Periodismo de la misma universidad. Imparte la asignatura Locución Informativa en el Grado de Periodismo, Locución en Televisión en el máster de Periodismo Multimedia de El Correo-UPV/EHU y Comunicación Emocional en el Máster de Comunicación Multimedia de EITB-UPV/EHU. Actualmente es Vicedecana de Comunicación y Relaciones Externas de la Facultad de Ciencias Sociales y de la Comunicación de la UPV/ EHU. terese.mendiguren@ehu.eus, https://orcid.org/0000-0003-3092-6608
} 
ABSTRACT: The emergence of social media has provided footballers a novel and highly effective means of reaching out to and interacting with followers. This new twist in the relationship between players and fans has sparked recent debate (Cleland, 2009) on players' attempts to connect with sports audiences and publicize their brand images via Twitter (Hutchins, 2011).

This research analyses aspects of the Twitter behaviour of the five football players who compete in the major European leagues with the greatest number of Twitter followers such as how these athletes relate to their fans, who they talk to and what they talk about via this medium in order to determine how these individuals use Twitter to build personal brands and forge deeper connections between themselves and the clubs they play for and fans.

Content analysis was used to detect message dissemination patterns and identify the main protagonists of Twitter conversations examined. Semantic networks and hashtag use were also analysed to identify significant correlations between words. NodeXL, one of the most widely employed open code software programs in social network analysis was used for this part of the analysis (Hansen, Shneiderman \& Smith, 2010).

One of the main uses they make of Twitter is linked to self-promotion. In addition, the profiles of these football players often support solidarity initiatives and campaigns.

Keywords: football; Twitter; player; fans; conversation; branding; content analysis; NodeXL; self-promotion.

\section{Introducción}

En las últimas décadas, el periodismo deportivo ha vivido un importante desarrollo en sus estructuras, canales y modos de producir contenidos, y ha obtenido un creciente protagonismo hasta afianzarse hoy en día como la tipología informativa de mayor alcance social en todo el mundo (Rojas, 2014; Boyle, 2017). Los contenidos deportivos constituyen una temática que despierta el interés de audiencias millonarias. La gente reclama deporte y, en consecuencia, quiere estar informada (Herrero \& Romero, 2015). Es el producto informativo de mayor interés colectivo y éxito social. Y no sólo eso, es también capaz de intensificar esa sensación de pertenencia a una comunidad (Hernández, Osorio, \& Zapata, 2013), forjando estrechos vínculos entre las personas a las que se dirige y contribuyendo a conformar identidades nacionales (Rowe, 2013).

Los contenidos deportivos actúan también como reclamo para anunciantes y patrocinadores. En el caso de la televisión, por ejemplo, el deporte ofrece numerosas ventajas y atractivos. Proporciona programas relativamente baratos, de limitada complejidad productiva y de alta rentabilidad dadas sus audiencias; y representa importantes valores añadidos para las estrategias de las cadenas de televisión y para sus anunciantes (Moragas, 1999: 77).

Según el profesor Knut Helland de la Universidad de Bergen, la mayor parte del periodismo deportivo actual es publicidad editorial. Los contenidos deportivos están dominados por los tipos de deporte, las estrellas deportivas y los eventos internacionales que generan los mayores ingresos en parámetros como la publicidad, el patrocinio, el número de telespectadores y de espectadores en el estadio (Schultz Jorgensen, 2005). Se mueven grandes cantidades de dinero en torno a la puja de los derechos de emisión de los grandes eventos deportivos cada temporada (Frujak, Frawley. \& Bush, 2017; Rojas, 2018).

Pese a que hay autores que denuncian la inmadurez del sector del deporte en materia de comunicación frente a otros ámbitos empresariales (Sanahuja, 2012), el deporte se consolida como un fenómeno de naturaleza global, fundamentalmente por el alcance y seguimiento de las retransmisiones televisivas y, además, como consecuencia del desarrollo del entorno 2.0 y las redes sociales (Sanderson, 2011). Éstas últimas se convierten en plataformas universales de producción de contenidos, 
y en el canal más rápido y eficaz (Sanderson, 2008; Hull, 2014) para anunciar todo tipo de noticias que luego serán desarrolladas y ampliadas en los medios convencionales.

Los contenidos deportivos juegan un papel trascendental en la actual estructura de los medios de comunicación (Miller, 2001; Rowe, 2003; Boyle, 2006, Kase, De Hoyos, Sánchis, \& Bretón, 2007). Y no sólo eso, sino que la irrupción de la nueva realidad digital también ha propiciado la aparición de nuevos medios digitales dedicados al periodismo deportivo, que se aprovechan del alcance de las nuevas plataformas para cubrir con mayor especialización cualquier modalidad deportiva, satisfaciendo las necesidades informativas de la audiencia que no son cubiertas por los medios convencionales.

Sin embargo, pese a que los contenidos deportivos tienen un gran protagonismo en los medios, tanto convencionales como en línea, distintas investigaciones concluían que faltaba un estudio detallado y continuado del periodismo deportivo, el cual no gozaba de tanta notoriedad en comparación con otros temas (Boyle, 2006; Cokley, Patching, \& Scott, 2006; Boyle, Rowe, \& Whannel, 2010; Nicholson, Zion, \& Lowden, 2011). Incidiendo aún más en esta idea, los contenidos deportivos no han sido ampliamente estudiados cuando además se les relacionaba con el periodismo en línea (English, 2016).

Ahora bien, todo apunta a que esta tendencia parece dispuesta a dar un giro sustancial, más aún en los últimos años, con la proliferación de investigaciones centradas en la relación entre el deporte y los medios digitales desde perspectivas tan diferentes como las organizaciones deportivas, los deportistas, y los propios medios y sus profesionales; o incluso los vínculos que se establecen entre las diferentes modalidades deportivas y sus seguidores.

Estudios recientes se centran en el uso de las redes sociales por parte de atletas y organizaciones deportivas (Pegoraro, 2010; Browning \& Sanderson, 2012; Sellitto 2014), para la autopromoción, la autorrepresentación y la expresión personal. Se cuentan por millares los ejemplos de deportistas que se comunican con sus seguidores, periodistas o amigos a través de las redes sociales. De hecho, las diferentes plataformas sociales son usadas habitualmente en un intento por incrementar los niveles de interactividad entre los seguidores de un deporte, un club o un deportista (Birkner \& Nöelleke, 2016; Billings, Qiao, Conlin, \& Nie, 2017).

Muchos de esos contenidos son a menudo banales, carentes de valor informativo o de información controvertida. Sin embargo, en ocasiones, son precisamente estas características las que hacen que este tipo de mensajes destaquen y lleguen a millares de personas, mostrando una imagen más real, más íntima de la celebridad deportista. En definitiva, la distancia entre el deportista de élite y sus seguidores desaparece.

La presente investigación se llevó a cabo para determinar si los futbolistas mantienen diálogos significativos y transparentes e intercambian información con los aficionados a través de Twitter; si los mensajes tuiteados por los jugadores estimulan las conversaciones bidireccionales con los usuarios con los que se comunican a través de esta plataforma (otros jugadores, periodistas, medios de comunicación, empresas, aficionados, etc.) y de qué suelen tratar sus conversaciones en línea.

El principal objetivo de los investigadores ha sido discernir si las estrellas del fútbol tratan de atraer a los aficionados a través de Twitter o si simplemente utilizan la plataforma como un medio para relacionar sus carreras deportivas con sus actividades comerciales fuera del campo de juego, de una manera interesada que no invita ni estimula la conversación, la crítica o el intercambio de opiniones (Weeks, Ardévol-Abreu, \& Gil de Zuñiga, 2017).

Igualmente interesante resulta estudiar la forma y el contenido de los mensajes de Twitter publicados en esas cuentas y la posible presencia de redes semánticas y correlaciones entre palabras para descubrir pautas ocultas de significados. 
Este trabajo se ha planteado las siguientes hipótesis:

H1 - Partiendo de la idea de que los deportistas en general utilizan las redes sociales para relacionarse con sus seguidores (Pieper, 2013; Sanderson, 2013), los jugadores de fútbol también interactúan a través de Twitter con sus fans de manera directa, sin la intermediación de sus clubes, dentro de una estrategia de construcción de una imagen pública predeterminada.

H2-Las redes sociales brindan oportunidades necesarias para que los futbolistas puedan difundir el conocimiento de su propia imagen de marca y mejorar los lazos emocionales con sus seguidores.

H3-Los perfiles en Twitter de los futbolistas constituyen un espacio ideal para mostrar su faceta más familiar, más solidaria (mediante el apoyo de determinadas campañas promovidas por ONGs, etc.) que contribuye a humanizar su figura.

H4-Ahora bien, la notoriedad de las estrellas del fútbol ayuda a posicionar determinados productos en el mercado y a promover que los seguidores se sientan identificados con esas marcas y los deportistas que los impulsan.

\section{Marco teórico}

El fútbol ha pasado de ser una mera competición a convertirse en uno de los deportes más populares (Lardo, Dumay, Trequattrini, \& Russo, 2017) en el que se observa que la lealtad a unos colores es mucho mayor que en otras actividades deportivas (Adamson, Jones, \& Tapp, 2006). Se ha convertido en un espectáculo deportivo en el que confluyen intereses variados y públicos diversos. El fútbol es un gran negocio que solo en el mercado europeo generó ingresos superiores a los 28.000 millones de euros la temporada 2017/2018, según el informe Annual Review of Football Finance.

$\mathrm{Y}$ de la misma manera que ha evolucionado el fútbol, las relaciones entre los clubes, sus seguidores y los medios se ha desarrollado también, lo que ha originado que la cobertura del fútbol constituya un elemento prioritario en los medios de comunicación en detrimento de otras especialidades deportivas (González, 2004).

Tal y como recogen Post, Preston, \& Sachs (2002), los clubes de fútbol y los medios de comunicación poseen intereses comunes: los primeros, difundir mensajes con la intención de que lleguen a su público objetivo; los segundos, obtener información que les permita desarrollar su actividad profesional. Se trata de una relación en la que ambos consiguen beneficios (Helland, 2007; Olabe, 2016).

Pero igual de trascendentales son las relaciones que establecen con los medios como los vínculos que establecen con sus seguidores. (Cleland, 2009). Según Hopwood (2010), la comunicación de los clubes se entiende desde un modelo integral que contribuye a que se relacionen con sus públicos de una manera más efectiva (Ledingham, 2003).

En la medida en que esas relaciones son sólidas, el rendimiento económico de los clubes se ve favorecido, al igual que el de los propios futbolistas (Rosen, 1981). Y es que son varios los factores que contribuyen a resaltar ese valor económico: el éxito en el terreno de juego, los ingresos, la asistencia a los campos, la audiencia de las transmisiones e incluso el tamaño de su base de seguidores en todo el mundo (Boor et al., 2016). Tal y como recoge Antezana (2003, p. 88), “el fútbol no sólo sucede dentro de la cancha, sino que también sucede fuera, pues entendiéndolo como espectáculo, es ininterrumpido y multifacético".

El fútbol, que es el deporte global más seguido y con un mayor grado de audiencias (Ginesta, 2011), no escapa a esta coincidencia de intereses diversos y enmarañados e igualmente mantiene una presencia permanente en el ecosistema comunicativo (Castillo, Fernández, \& Castillero, 2016), en el 
que los medios de comunicación no son los únicos intermediarios entre clubes y aficionados. Ya no son los únicos transmisores de su identidad corporativa y de su gestión empresarial (Olabe, 2009). La información en torno al fútbol brota desde los medios y sus profesionales, e igualmente desde las propias entidades deportivas, los futbolistas, los seguidores del equipo o incluso las empresas patrocinadoras (Ginesta, 2010). De hecho, la relación que los periodistas mantienen con los clubes se han ampliado a otros públicos objetivos como los propios deportistas, a quienes no interesa perderlos como fuentes informativas (Rowe, 2004).

La influencia de la televisión (Rowe, 1996) y de los nuevos medios sociales, junto con las fuerzas de la internacionalización y la globalización (Dolles \& So'derman, 2013), ha transformado la relación entre las organizaciones deportivas y los medios (Schultz \& Sheffer, 2010). Igualmente, el modelo comunicativo de los clubes de fútbol ha cambiado. La práctica totalidad de los equipos de fútbol han apostado por integrar en sus estructuras empresariales el departamento de comunicación, el cual, en muchas ocasiones, desempeña también otras funciones más allá de las relaciones públicas. La puesta en marcha de nuevos soportes (webs corporativas, canales de televisión o radio, o redes sociales, entre otros), que se suman a los modelos tradicionales de comunicación, ha generado un nuevo ecosistema informativo en torno a la actualidad de los clubes en el que los medios tradicionales pierden su hegemonía (Ginesta, 2009; Prudkin, 2010). Los teléfonos móviles y las tabletas van a añadir una dimensión adicional a este fenómeno y se van a convertir en uno de los actores principales de lo que se ha venido a llamar economía de los contenidos deportivos mediáticos (Hutchins y Rowe, 2009), que en la actualidad se caracteriza por la creciente internacionalización; la multiplicación de plataformas; y la irrupción de nuevos actores que producen y distribuyen contenido a través de Internet y las redes sociales (Hutchins, 2014).

\subsection{Clubes de fútbol y redes sociales}

La relación cambiante entre los clubes de fútbol y sus seguidores ha sido objeto de debate reciente (Cleland, 2010). Los equipos han mejorado muchísimo en este ámbito, gracias fundamentalmente a la irrupción de las redes sociales, utilizadas como herramienta de comunicación organizacional, y que cumplen una función importante en la expansión y difusión de sus propias marcas, además de una nueva manera de interactuar con sus públicos de una forma inmediata y eficaz.

Las redes sociales han logrado una gran importancia en los clubes gracias a la relación directa que establecen con sus seguidores, quienes buscan informarse directamente de su equipo favorito, más allá de lo que acontece en el terreno de juego los días de partido, y además quieren interactuar con él. Uno de los objetivos más importantes de los clubes profesionales en la actualidad es la fidelización de los seguidores y simpatizantes (Cano, 2017; Vale \& Fernandes, 2018; Naraine, Pegoraro \& Wear, 2021); lograr que éstos revivan una experiencia holística del fútbol como producto (Thrassou; Vrontis, \& Kartakoullis, 2012).

En una primera fase, las estrategias comunicativas de los clubes se limitaban principalmente a relacionarse únicamente con los medios. Con posterioridad, se pasó a una etapa caracterizada por la inclusión de técnicas 2.0 que supuso no sólo la expansión de medios interactivos sino también la adaptación de las estrategias de comunicación a las nuevas maneras de relacionarse con todos los agentes que participan en el nuevo ecosistema comunicativo. Internet y los nuevos medios sociales posibilitan el flujo multidireccional de mensajes y mayores posibilidades de selección, expresión y comunicación (Sotelo, 2012, p. 218). Y la crisis económica, como en el caso español, también ha afectado a los clubes profesionales de fútbol, obligándoles a reinventarse en muchos ámbitos, teniendo mucha importancia en este contexto la gestión de la comunicación que realizan estas entidades en el medio internet, especialmente en las principales redes sociales (Grimmer \& Clavio, 2019). 
Gran parte de los ingresos de los clubes de fútbol continúan estando marcados por los derechos de la televisión, los contratos publicitarios o los ingresos por taquilla. Pero desde hace muy pocos años, empiezan a darse cuenta de que las redes sociales constituyen también un excelente generador de ingresos y posible fuente de financiación en su estrategia de marketing (Calzada, 2012).

Son muchos los beneficios que las redes sociales aportan a los clubes de fútbol (Sotelo, 2012):

- Maximiza los procesos de participación de los seguidores

- Convierte las entidades deportivas en organizaciones más participativas y transparentes

- Aumenta la notoriedad

Ahora bien, hay quien reconoce que muy pocas entidades emplean las redes para dialogar con sus seguidores. Esa estrategia unidireccional por parte de los clubes supone una baja implicación comunicativa con los aficionados y simpatizantes (Castillo, Fernández, \& Castillero, 2016).

Sea como fuere, cada día son más los clubes de fútbol que usan las redes sociales en general y Twitter en particular para crear nuevas formas directas de comunicación entre éstos y sus seguidores (Price, Farrington, \& Hall, 2013; Yan, Watanabe, Shapiro, Naraine \& Hull, 2019). Ello responde a un deseo de fortalecer las relaciones profesionales, personales y comunitarias con sus públicos, quienes, junto con los jugadores, además de cuerpo técnico y gerencia, constituyen los principales recursos de la industria del fútbol (Shareef \& Davey, 2005).

Los clubes entendían que un desarrollo de las estrategias en las redes sociales podría generar interacción y participación, crecimiento y pertenencia a la comunidad, flujo de tráfico a sitios web oficiales y ganancias comerciales. Sin embargo, al desarrollar sus estrategias en las redes sociales tenían dos preocupaciones clave. La primera inquietud fue el control de la presencia de la marca y la imagen en las redes sociales, y cómo responder a las oportunidades que presentan los medios sociales para que los aficionados impacten en la marca. La segunda preocupación fue cómo lograr un equilibrio adecuado entre las estrategias que generan ingresos a corto plazo y las que generan lealtad a la marca a más largo plazo (McCarthy, Rowley, Jane, \& Pioch, 2014).

La presencia en las redes sociales posibilita a los clubes de fútbol llegar con facilidad a un público bastante importante, no sólo por la cantidad, sino también por su fidelidad. En el caso de Twitter, por ejemplo, algunas entidades tienen una cuenta oficial o varias, en diferentes idiomas, en función de sus públicos potenciales o sus intereses deportivos y empresariales (Lobillo \& Muñoz, 2016). Su empleo no se basa únicamente en crear un perfil en el que publicar noticias, sino en seguir una planificación estratégica que ofrezca además de información, promociones de productos, comercialización, etc. (Salinero, 2014). Esta praxis ya ha sido también analizada en otras disciplinas deportivas (Wang \& Zhou, 2015; Giron, 2015).

\subsection{Uso de Twitter por parte de los futbolistas}

En los últimos tiempos se ha producido un incremento rápido y generalizado en el uso de la plataforma de microblogging por parte de los deportistas que les posibilita comunicarse con sus públicos y crear poderosas marcas personales (Hutchins, 2011; Pegoraro \& Jinnah, 2012; Zamora, Sanahuja, \& Blay, 2015; Cano \& Paniagua, 2017; Coche, 2017). En el verano de 2009, un sitio de seguimiento de Twitter (www.trackingtwitter.com) reveló que Shaquille O’Neal tenía 1,75 millones de seguidores. Otras estrellas del deporte eran el ciclista Lance Armstrong (1,54 millones de seguidores) y el patinador Tony Hawk (1,2 millones), y el sitio de Twitter de la NBA contaba con 600.000 seguidores. Twitter posibilitaba a los aficionados y deportistas comunicarse directamente entre sí. Según 
Gregory, “Twitter satisface la sed de los aficionados de una conexión más estrecha con los grandes atletas" (2009: 16)

Ahora bien, no todos los grandes deportistas disponen de un perfil de Twitter con el cual poder interactuar con sus seguidores. Así, Messi, que lidera el ranking de los futbolistas mejor pagados en el curso 2018/2019, según cifras publicadas por la revista France Football, no ha abierto cuenta oficial en la red de microblogging. Ello no le impide, sin embargo, ser el tercer jugador más popular en las redes sociales, por detrás de Cristiano Ronaldo y Neymar Jr.

McCarthy, Rowley, Jane, \& Pioch (2014) destacan los beneficios de las redes sociales para las marcas a través de las relaciones que se establecen entre los clubes y sus seguidores. En este sentido, cada vez son más las marcas que emplean a jugadores famosos como imagen en Twitter y otras redes sociales para dar a conocer sus campañas publicitarias a través de ellos o de sus propias cuentas oficiales, si bien hay quien reconoce que los deportistas profesionales pueden no aprovechar las oportunidades promocionales que Twitter les brinda (Hambrick, Simmons, Greenhalgh, \& Greenwell, 2010).

En los últimos años, la modificación acontecida en la capacidad de comunicar que han posibilitado los medios digitales ha originado un cambio en la manera en que los deportistas se relacionan con sus audiencias en cuestión de segundos (Fernández \& García-Guardia, 2016, p. 116), en un deseo de mantener y reforzar la vinculación con sus seguidores (Marshall, 2010; Marwick \& Boyd, 2011; Lee \& Shin, 2012). Y ello ha propiciado, entre otras cuestiones, una pérdida proporcional del protagonismo del periodista frente al deportista, quien también facilita información relevante para el público. Ya no hay jerarquías y los límites entre el autor, fuente y protagonista del hecho noticioso son difusos.

Muchos clubes están empezando a definir políticas sobre cómo gestionar los perfiles de sus jugadores en las distintas redes sociales, ya que en algunas ocasiones sus seguidores superan en número a los de sus propios equipos. De hecho, la gestión de las redes sociales puede repercutir en las carreras profesionales de los futbolistas de élite (Birkner \& Nölleke, 2016, p. 13).

A través de la publicación de contenidos en las redes sociales los futbolistas muestran su lado más humano, comparten información de cualquier tipo, se relacionan con otros deportistas y comunican un hecho desde un punto de vista personal (Fernández \& García-Guardia, 2016). En definitiva, muestran a sus seguidores lo que sucede en su vida más personal (Gallagher, 2015), y ello influye de manera notoria en la percepción que los fans tienen de ellos (Kim \& Song, 2016), si bien estudios recientes también han demostrado que los seguidores pueden no estar tan interesados en los detalles personales de la vida de los futbolistas fuera del deporte (Lebel \& Danylchuk, 2014; Zimmerman, Johnson, \& Ridley, 2016); o que resulta poco probable que un jugador interactúe con todos sus seguidores (Lastra, 2014).

\section{Metodología}

La elección de Twitter, como ya hemos resaltado, se debe a que los deportistas muestran una predilección por la red de microblogging frente a otras plataformas para expresarse (Blaszka, Burch, Frederick, Clavio, \& Walsh, 2012). Pero además, investigaciones recientes apuestan por esta aplicación porque posibilita observar de modo sencillo los flujos de información entre usuarios y ofrece un interesante surtido de datos para investigaciones académicas (Del Fresno, Daly, \& Segado, 2016). Esta idea ya fue recogida con anterioridad por otros investigadores que mostraban Twitter como un buen laboratorio natural para estudiar los patrones de difusión de información (Bakshy, Hofman, Mason, \& Watts, 2011). 
Tabla 1. Cuentas analizadas

\begin{tabular}{|l|l|c|c|c|r|}
\multicolumn{1}{|c|}{ Nombre } & \multicolumn{1}{c|}{ Club } & Seguidores en Twitter & Siguiendo & \multicolumn{1}{c|}{ Usuario } & Tuits \\
\hline Cristiano Ronaldo & Juventus de Turín & 72,4 millones & 95 & @Cristiano & 3.156 \\
\hline Andrés Iniesta & F.C. Barcelona & 22,8 millones & 81 & @andresiniesta8 & 1.728 \\
\hline Gerard Piqué & F.C. Barcelona & 18,6 millones & 559 & @3gerardpique & 2.562 \\
\hline Neymar Jr & París Saint-Germain & 39,7 millones & 746 & @neymarjr & 41.100 \\
\hline Mesut Özil & Arsenal & 23,1 millones & 86 & @MesutOzil1088 & 1.377 \\
\hline
\end{tabular}

Fuente: Elaboración propia. Primer semestre de 2019

Para lograr una exploración rica y detallada de los contenidos de las cinco cuentas, se recurrió a la técnica del análisis de redes sociales (ARS o SNA, por el término en inglés, social network analysis), que posibilita identificar las estructuras que se crean en las redes sociales, ayudando a un estudio formal de las relaciones que surgen entre actores que la conforman (Sanz, 2003). Esta estrategia metodológica permite explicar fenómenos de orden social que acontecen entre los participantes de una red (Pérez, Santos \& Meso, 2021) y ha sido estudiada profusamente por distintos autores (Freeman, 2004; Borgatti et al., 2009).

Las cuentas analizadas fueron las de los cinco futbolistas que juegan en diferentes ligas europeas con mayor número de seguidores en Twitter. En concreto, se cogieron los perfiles de Cristiano Ronaldo (Juventus de Turín), Andrés Iniesta (F.C. Barcelona), Gerard Piqué (F.C. Barcelona), Neymar Jr. (París Saint-Germain) y Mesut Özil (Arsenal). Iniesta es actualmente jugador en un equipo en Japón pero estaba en el F.C. Barcelona en el momento en que se realizó la investigación.

Para conocer los patrones de difusión de sus mensajes e identificar con qué personas se relacionan y sobre qué hablan se ha empleado el software NodeXL, uno de los principales programas de análisis de código abierto para redes (Hansen, Shneiderman, \& Smith, 2010; Ahmed \& Lugovic, 2019) y que ha sido utilizado con éxito en multitud de investigaciones.

La extracción se realizó durante el primer semestre de 2019 y se capturó toda la actividad generada desde la creación de dichos perfiles, un total de 2.254 vértices (cuentas con las que interactuaron) y 12.784 relaciones (interacciones).

Se analizaron tres apartados concretos: actividad, interacción y contenido (Pérez, Meso, \& Mendiguren, 2018). La actividad se midió mediante el número de mensajes que publicaron los futbolistas en sus perfiles, identificándose a quién pertenecía la cuenta con la que éstos interactuaban. En la interacción, por su parte, se analizaron los retuits, las menciones y las respuestas. A mayor cantidad de estos elementos, más alto es el interés por parte del futbolista por dialogar con otras personas, instituciones, empresas o medios de comunicación. Por último, se examinaron los contenidos de los mensajes que los jugadores de fútbol intercambiaron, prestando especial atención a las redes semánticas y redes de hashtags y tratando de descubrir pautas ocultas de significado en las asociaciones de palabras presentes en los mensajes.

\section{Resultados}

\subsection{Actividad de la cuenta}

Twitter, quizás debido a su naturaleza inmediata, es una de las plataformas sociales dominantes en el mundo del deporte, con deportistas, entrenadores, seguidores y profesionales de los medios de 
comunicación que mantienen cuentas e interactúan entre sí (Browning \& Sanderson,2012; Sanderson \& Kassing,2011).

La red de microblogging es una excelente herramienta para que los seguidores de un deporte se informen sobre él a través del intercambio de informaciones entre ellos (Wang, 2013); o para interactuar con una celebridad de cualquier modalidad deportiva (Highfield, Harrington, \& Bruns, 2013), a la que suelen ver como un experto en la materia o un modelo a seguir (Clavio \& Kian, 2010).

El perfil de Cristiano Ronaldo es el que más relaciones contabilizó, seguido por el de Neymar Jr y Gerard Piqué. En los casos de Neymar, Ronaldo y Piqué la mayoría de las relaciones son con sus seguidores. El segundo grupo de cuentas con más interacciones en el perfil de Neymar Jr es el perteneciente a deportistas, en el que más de dos tercios son futbolistas. Le siguen en tercer lugar las cuentas de empresas como@nikefootball; en cuarto lugar, los periodistas y medios de comunicación como@foxsportsbrasil; y en quinto lugar organizaciones y actividades solidarias como@savechildrenuk.

En lo que refiere a Cristiano Ronaldo, tras los fans, se situaron las cuentas pertenecientes a empresas como@tagheuer, seguidas por las de deportistas (en los que primaron los futbolistas) y por las de periodistas y medios de comunicación como@menshealthmag.

En el caso de Gerard Piqué, tras los fans, el grupo con más interacciones fue el de deportistas (aproximadamente la mitad fueron futbolistas) seguido por los periodistas y medios de comunicación como@marca.

En los casos de Andrés Iniesta y Mesut Özil hay que señalar que el grupo de los fans no fue el más numeroso. En ambos perfiles, el grupo con el que más interactuaron fue el de los deportistas (casi la totalidad futbolistas), seguido por las interacciones con empresas.

Hay que apuntar también que en las cuentas de los cinco jugadores se observó la presencia, en mayor o menor medida, de un grupo de organizaciones o actividades solidarias, siendo Andrés Iniesta el que mantuvo un mayor contacto con ellas y Gerard Piqué el que menos.

Otro aspecto a destacar es que hay tres actores que conectaron a cuatro de los futbolistas estudiados (Figura 1). La retirada de Kobe Bryant en 2016 (@kobebryant) fue lo suficientemente importante para que Neymar, Iniesta, Piqué y Özil le dedicasen diferentes menciones. Por ejemplo, Neymar se dirigió a él de la siguiente manera: "Heros come and go, but legends are forever. @kobebryant, you are eternal...Thanks for everything!!". Iniesta también comentó: "Esta semana se ha despedido uno de los más grandes... Te deseo lo mejor @kobebryant!!”. Por su parte, Özil escribió: “One of the greatest players of all time will end his career! Hats off to what you've achieved in your career! @ kobebryant".

El segundo actor en común fue @nike. Neymar, Iniesta, Piqué y Ronaldo conversaron con la empresa americana. Por ejemplo, Ronaldo comentó: “Thanks @Nike for this amazing birthday gift!”. A su vez, Iniesta apuntó: "Todo empieza en Fuentealbilla. Nacer en un pueblo pequeño no es un límite para alcanzar tus metas. @Nike \#JustDoIt”. En la misma línea fue el tuit de Neymar: "My story began in Mogi das Cruzes, with my family by my side. Now, I walk with all of Brasil. @nike \#JustDoIt". También el de Piqué: "I was born in Barcelona. Soon I had a Dream. I just did it. @ nike \#JustDoIt". 
Figura 1. Actores que conectan a los 5 futbolistas

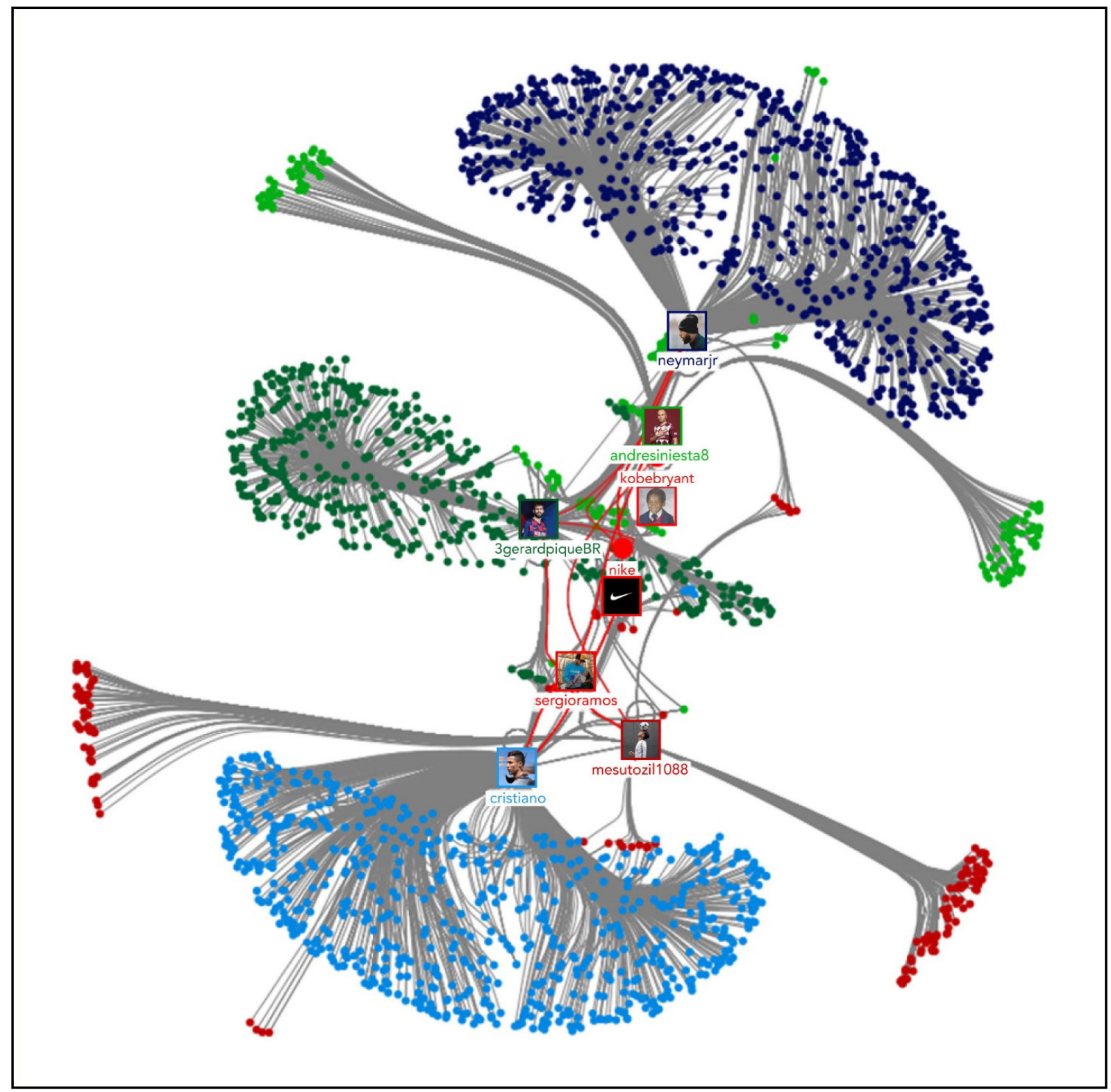

Fuente: Elaboración propia

Sergio Ramos (@sergioramos) fue el tercer actor que más coincidencias generó entre los futbolistas estudiados: Iniesta: "RT@SergioRamos: En la tierra de un grande. @andresiniesta8!! In the land of a great man". Piqué: "I accepted the ALS \#IceBucketChallenge! I challenge @SergioRamos@ marcmarquez93@cesc4official”. Ronaldo: “RT@SergioRamos: Good morning...! Taking off to Turin. Let's go team! Hala Madrid!!@Cristiano@GarethBale11”. Özil: “Happy Birthday,@SergioRamos! Miss you, Bro! 6 ".

\subsection{Interacción}

Parece lógico pensar que los usuarios tienden a utilizar Twitter para crear relaciones personales con otros usuarios y para afianzar la idea de pertenencia a una comunidad mediante el intercambio de información y el diálogo entre las partes. Hay quienes para fortalecer esas relaciones crean contenidos y/o quienes simplemente responden a los comentarios que otras personas hacen, 'mueven' esos 
contenidos mediante el empleo de los retuits, o mencionan a otros usuarios. Todo ello es válido para construir relaciones e interactuar, si bien hay quien se muestra crítico y destaca las limitaciones en la estructura de Twitter que actúan en contra de los ideales de la teoría del discurso de Habermas (O’Hallarn, Shapiro, Wittkower, Ridinger, \& Hambrick, 2019).

Tras examinar las cuentas de los cinco futbolistas se observó que la mención fue la forma de interacción más utilizada (se incluyó el retuit porque cada vez que se redifunde un mensaje de una persona en Twitter también se cita su nombre de usuario para que se dé por aludido).

El empleo de las menciones denota que los futbolistas tratan de mantener el contacto y relacionarse con otros usuarios, aspecto que refuerza el vínculo entre ellos y deja de manifiesto la utilidad de Twitter como vehículo de comunicación para acceder a la gente, contactar, preguntar, consultar, ser corregido, aclarar dudas...La mención también cumple otra función en algunos mensajes: señalar el origen del contenido y, en consecuencia, reconocer la autoría del mismo.

Esta opción fue la preferida de jugadores como Cristiano Ronaldo (RT @LarryFitzgerald: \#TeamFitzgerald I need u to Download the best iPhone game out "Heads Up w/ Cristiano" \& follow "LarryFitzgerald" in ...), Gerard Piqué (Campió del món @marcmarquez93! World Champion Marc Márquez! Congratulations! \#motoGP) o Mesut Özil (Good luck to my former teammates @realmadrid! @ChampionsLeague \#ucl).

En el caso concreto de los retuits, la explicación de su uso por parte del futbolista habría que buscarla en el interés en el tema exacto del retuit, la relevancia percibida que éste puede tener para sus propios seguidores o la coincidencia en la opinión, tal y como recogen algunas investigaciones recientes (Boehmer \& Tandoc, 2015).

El diálogo en Twitter generalmente se realza mediante el empleo de las respuestas (Small, 2011). El uso del símbolo@ se utiliza para responder a otro usuario o para la inclusión de otro usuario en una conversación en curso (Lovejoy, Waters, \& Saxton, 2012). En este punto hay que destacar el uso de la respuesta como forma de interactuar con los usuarios por parte de Neymar Jr. El jugador brasileño recurre a dicha opción en un $36 \%$ de las ocasiones frente a compañeros como Ronaldo (5,9\%), Piqué (5,7\%), Özil (1,5\%) o Iniesta $(0,2 \%)$.

\subsection{Contenidos}

El análisis de las asociaciones de palabras más frecuentes presentes en los tuits de los cinco futbolistas permitió descubrir patrones de significados en el contenido de los mensajes. Unas palabras estuvieron más conectadas que otras y permitieron establecer los hilos de conversación más relevantes.

En la cuenta de Cristiano Ronaldo destacaron tres hilos de conversación (Figura 2). La asociación de palabras más frecuente fue "thanks+support" y guardó relación con acontecimientos como el nacimiento de su hijo el 17 de junio de 2010 (“@lukejvaughn@inagaki@syilabebe Thank you for the support...”) o con su participación en competiciones como la World Cup ese mismo año: “@ Scarlett_CR thanks for the support. Follow Team Portugal for the Cup!". La segunda asociación de palabras más frecuentes en los tuits fue la de "real+Madrid+hala" ya que el jugador portugués aprovechó a menudo para hablar de su equipo: "Real Madrid 6 - Deportivo La Coruña 1". Además, el lema que acompaña al club merengue también fue muy repetido en las interacciones con otras cuentas: “Thank you@mmariajose10@Cristiano You are my favorite soccer player! and real madrid is my favorite team! good luck on monday! HALA MADRID!". La tercera conexión entre diferentes ideas giró en torno a "hi+asked+hello" ya que un 3,5\% de los mensajes (que fueron difundidos entre enero y octubre de 2014) presentaron la siguiente estructura: "You asked: Hello from Moscow, Russia! Good luck in this season Cristiano;)". 
Figura 2. Palabras más conectadas de la cuenta de Cristiano Ronaldo

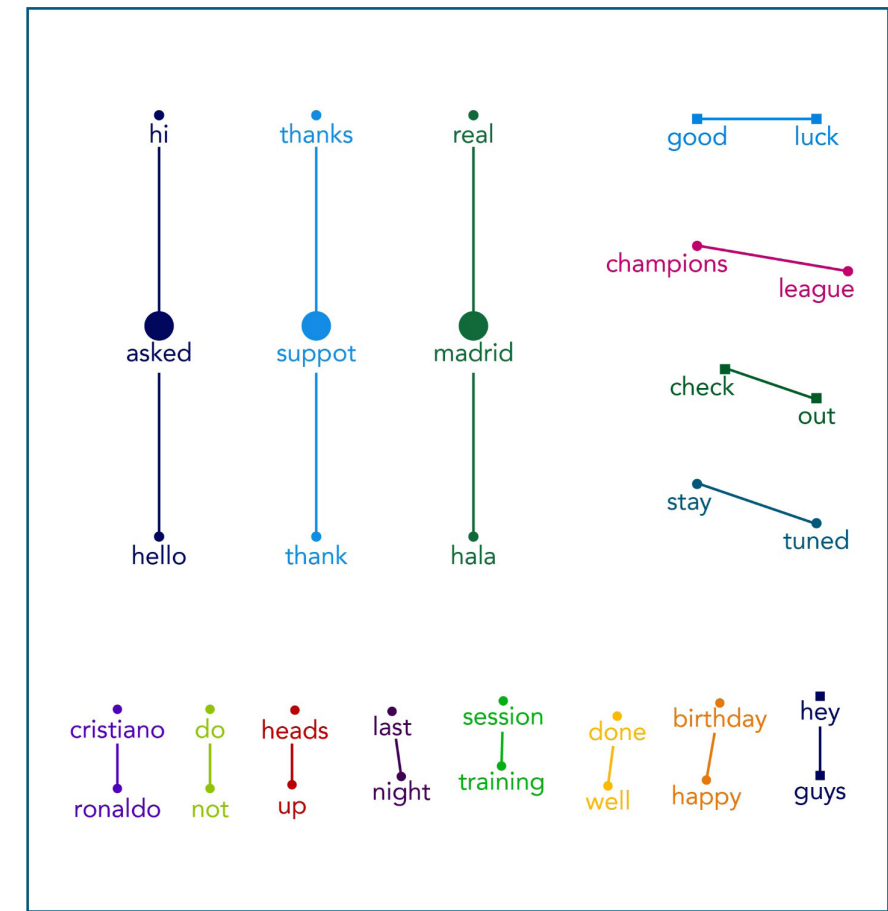

Fuente: Elaboración propia

En el caso de Gerard Piqué (Figura 3) la conexión más fuerte fue la de "moc+moc", una muletilla que el jugador compartió con Cesc Fábregas y Carles Puyol y que tuvo su origen en un vídeo online que les hizo mucha gracia. "Menudo crack@ortizbernal!! Justo cuando acabó el partido me preguntó que significaba Moc moc!! Te envío un Moc moc crack!!”.

Figura 3. Palabras más conectadas de la cuenta de Gerard Piqué

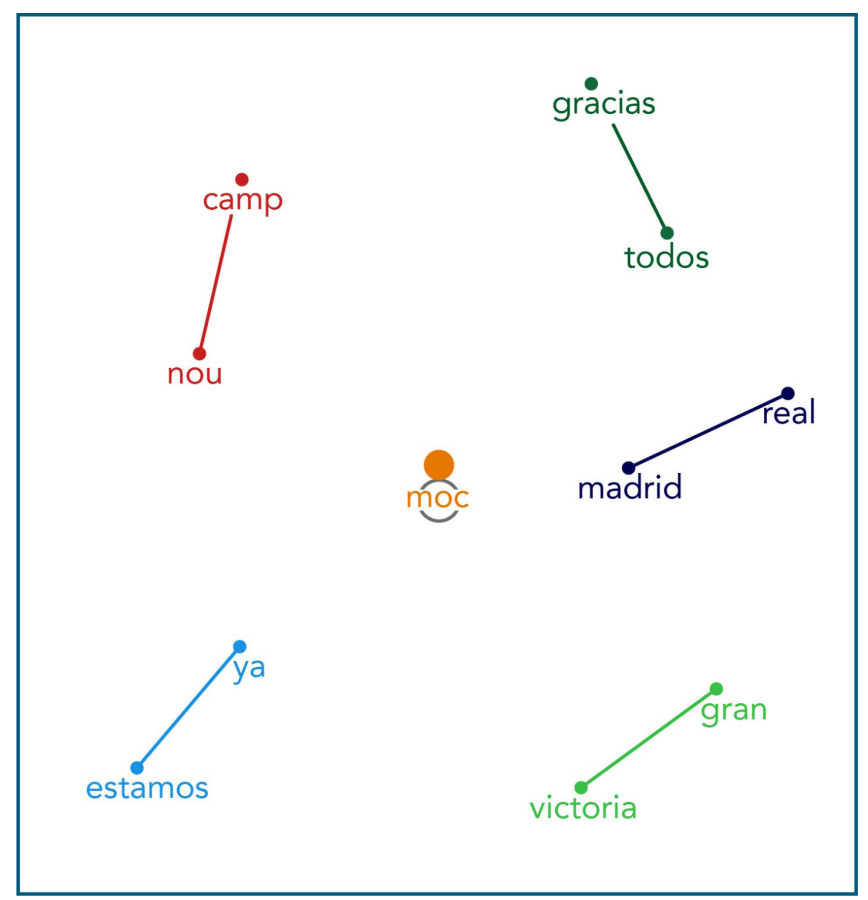

Fuente: Elaboración propia 
Para Andrés Iniesta (Figura 4), entre las conexiones más importantes destacaron "muchas+gracias+todos". Los agradecimientos fueron una constante en sus tuits: "Un orgullo poder presentar junto a los míos, el nuevo "Corazón Spumante Moscato"! Gracias a todos! @BodegaIniesta”. Además, también presentaron una fuerte vinculación términos como "buenas + noches + sensaciones" y "os+dejo+foto", ya que a menudo publicó sus mensajes acabada la jornada donde aprovechó para enviar una foto o un video a sus seguidores: "Buenas noches amigos, os dejo este vídeo de mi amigo@13_Pinto... Gran labor de @pallapupas en los hospitales" u "Hoy ha sido mi segundo entrenamiento con el grupo. Y con muy buenas sensaciones! Os dejo una foto con mi compi @ DaniAlvesD2".

Otros hilos de conversación ("gran+partido+victoria") hicieron referencia a los triunfos del F.C. Barcelona: "Gran partido y el pase a semis conseguido. He podido disputar unos minutos y disfrutar del gran juego del equipo" o también "Gran victoria! contento por el gol pero aún más contento por el juego que hemos hecho, que gran partido!!". Por último, también fueron frecuentes en sus mensajes los emparejamientos de palabras como "vamos+equipo+barça": "Seguimos sumando de 3 en 3, en este mes se decide todo!! Vamos equipo!".

Figura 4. Palabras más conectadas de la cuenta de Andrés Iniesta

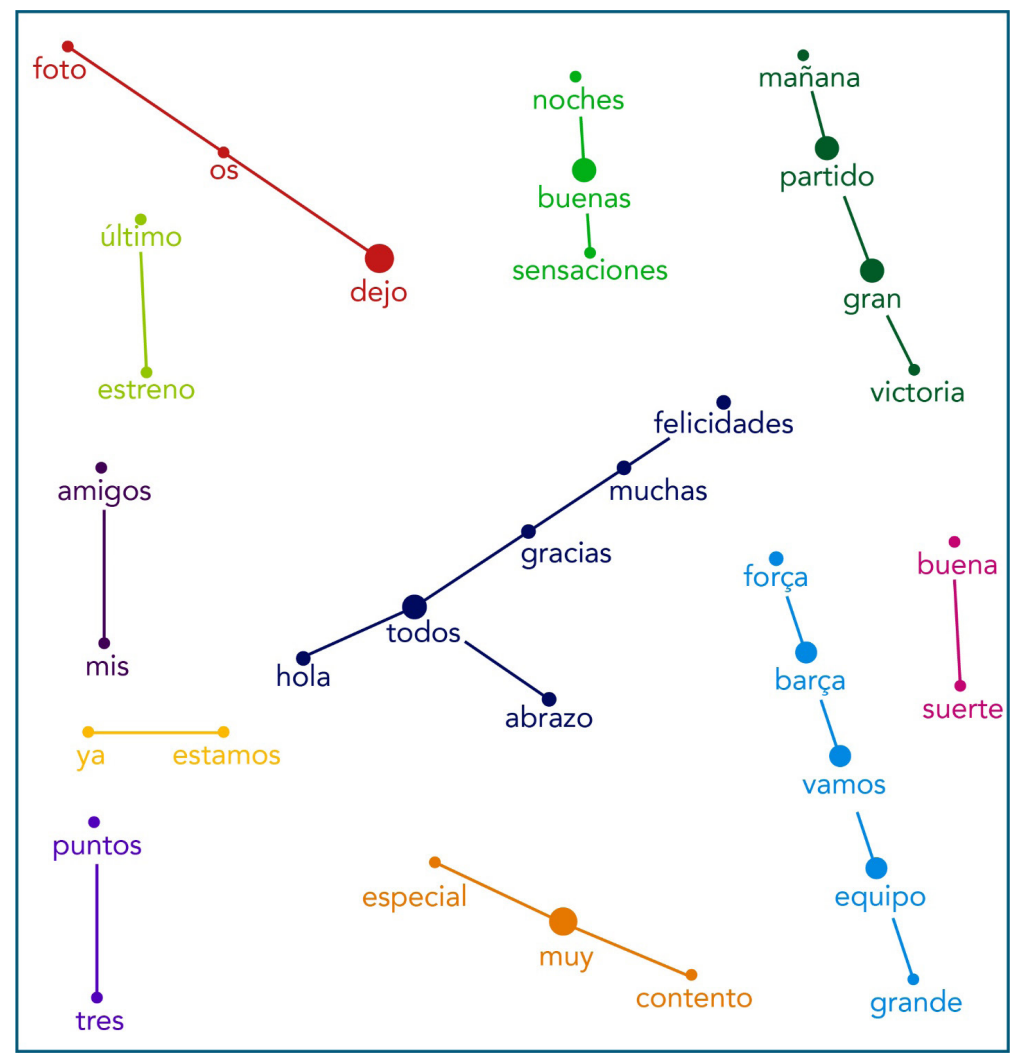

Fuente: Elaboración propia

En lo que se refiere a Mesut Özil (Figura 5), las alusiones a su antiguo equipo ("real+Madrid+hala") son las más significativas: “Good luck to my former teammates@realmadrid! @ChampionsLeague \#ucl”. 
Figura 5. Palabras más conectadas de la cuenta de Mesut Özil

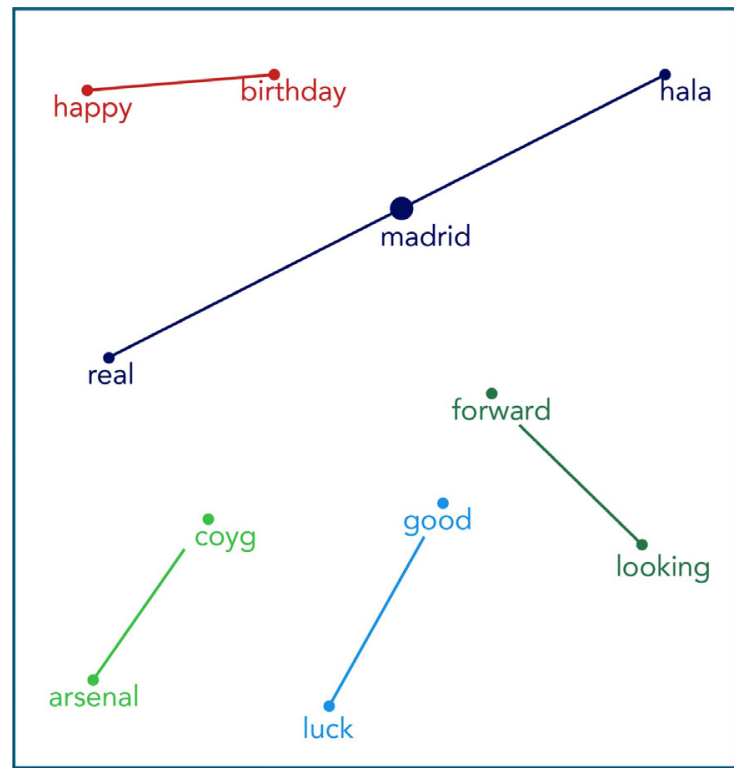

Fuente: Elaboración propia

Por último, el análisis de las asociaciones de palabras más frecuentes presentes en los tuits de Neymar (Figura 6) permite descubrir los siguientes patrones de significados en el contenido de sus mensajes. Palabras como "agora+só+falta+virar+craquedaclaro" y "e+ganar+carro+cadastre+concorra", relacionadas con un sorteo de una empresa de telecomunicaciones latinoamericana, estuvieron más conectadas que otras y destacaron entre los hilos de conversación más relevantes: “@ Soumaille agora só falta virar \#CraqueDaClaro e ganhar o carro. Cadastre-se e concorra".

Figura 6. Palabras más conectadas de la cuenta de Neymar Jr.

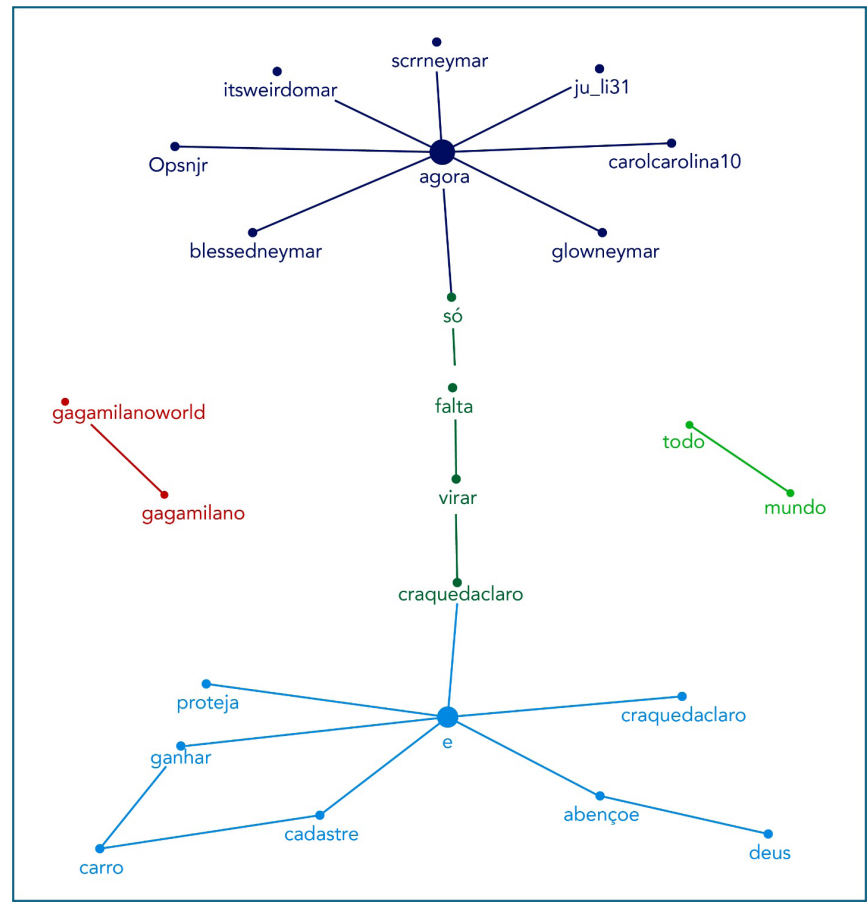

Elaboración propia 
Un recurso para aumentar la visibilidad de los mensajes de un perfil y despertar interés en más usuarios, ayudando a incrementar su participación, es emplear un hashtag o etiqueta. Convierte cualquier palabra o grupo de palabras que la siguen en un vínculo de búsqueda. Es una herramienta indispensable para aumentar la difusión de información relevante sobre noticias, productos, eventos y tendencias. De esta forma se organiza el contenido y es posible hacer el seguimiento de temas en concreto a partir de palabras clave. Según Cooper (2013), añadir uno o dos en un mensaje aumenta hasta un $21 \%$ las probabilidades que tienen de ser encontrados en una búsqueda y generar interacción.

En otras ocasiones, el empleo del hashtag sirve para contextualizar mejor el mensaje. Gracias a la etiqueta, todos los mensajes sobre un mismo tema se agrupan, de manera que el lector podrá acceder a toda la cadena de mensajes en torno al mismo acontecimiento.

Igualmente, la opinión de los usuarios se convierte en parte de los contenidos de los soportes analizados y cobra especial importancia el uso de la peculiar etiqueta.

Muchas grandes marcas que tienen cuentas de Twitter crean hashtags con el fin de fomentar campañas y promover eventos. Y es que el uso de etiquetas es una oportunidad fantástica para monitorizar las conversaciones de los usuarios en las redes sociales sobre un tema determinado, e identificar cuáles son los contenidos más relevantes.

Neymar Jr recurrió a la 'almohadilla' \# en el 69,4\% de sus mensajes, seguido por Mesut Özil, con un $66 \%$, Cristiano Ronaldo, con un $28 \%$, Gerard Piqué, con un 23,5\% y por Andrés Iniesta, con un $15,5 \%$.

Las marcas deportivas buscan constantemente captar la atención de los potenciales consumidores. Uno de los métodos más habituales es lograr una alianza con deportistas y poner en marcha campañas de promoción valiéndose de sus cuentas en las redes sociales (Brison, Byon, \& Baker, 2016). Casi todos los futbolistas analizados han empleado el hashtag para una acción de marketing en particular, con el claro objetivo de reforzar la campaña y la marca. Este tipo de etiquetas son utilizadas para promocionar un producto. Es el caso, por ejemplo, de Andrés Iniesta y Cristiano Ronaldo, quienes a través de sus tuits tratan de destacar las cualidades de las botas de fútbol que emplean.

Casualidad o no, los dos futbolistas, rivales deportivos, son, a su vez, dos de los principales estandartes de la firma Nike y jugaron un papel protagonista en las distintas campañas publicitarias, valoraron positivamente los citados modelos de botas.

Neymar, por su parte, se ha convertido en el nuevo embajador de la marca de relojes Gaga Milano, con un contrato hasta 2020.

Destaca también el empleo de hashtag de contenidos por parte de los futbolistas incluidos en el estudio para tratar de conectar directamente con un público objetivo, con el propósito de llamar claramente la atención de los usuarios y atraer a multitud de interesados. Es el caso de Mesut Özil, jugador del Arsenal, quien además de utilizar la etiqueta \#afc, en clara alusión al equipo en el que milita, emplea asiduamente \#coyg, acrónimo del club inglés "Come On You Gunners” o \#yagunnersya.

O de Gerard Piqué y el empleo de \#fcblive para destacar, entre otras cuestiones, los logros deportivos del FC Barcelona.

Conviene también señalar el empleo por parte de los jugadores analizados de hashtags en los que, de alguna manera, manifiestan sus sentimientos o estados de ánimo, y que suelen ser aquellos que también causan un gran impacto entre sus seguidores. Es el caso de Neymar, con su \#tamojunto, o Iniesta, con \#familia o \#felicidad. 
Cristiano Ronaldo, por su parte, aprovecha los hashtags para celebrar la consecución de una cifra redonda de seguidores, como son \#celebrate15 o \#weare20million.

Por último, merece una mención la utilización por parte de Gerard Piqué de un hashtag que provocó un gran revuelo en las redes sociales: \#eldeloscuadros. Nadie sabe de quién se trataba ni qué pretendía decir con sus dos dedos índices apuntando hacia arriba en una fotografía en la que los famosos eran Shakira y Gerard Piqué, confirmando aparentemente su relación, y Puyol y su novia, Malena Costa.

Sin embargo, el anónimo chico de la camisa de cuadros que aparecía en la parte inferior derecha de la imagen dio lugar a toda clase de bromas y suposiciones descabelladas. Y tuit tras tuit no solo les robó el protagonismo, sino que causó auténtico furor en Twitter, llegando a convertirse en número uno de los trending topics. El mismo día de su nacimiento, \#eldeloscuadros ya contaba con su propia página de Facebook.

Gerard Piqué comenzó a bromear con la figura de \#eldeloscuadros en Twitter y a generar expectación entre los aficionados a esta red y al equipo blaugrana. Desde que colgó la foto en la red de microblogging, el defensa del Barcelona fue avivando el juego de tuits sobre el personaje.

Una de las partes más interesantes de Twitter es la interacción con otros usuarios. Las conversaciones son una de las claves del éxito en esta red social, ya que facilita el intercambio de información y opiniones con otros usuarios. Las maneras más habituales son a través de las respuestas, cuando se responde a alguien, y las menciones, conversaciones públicas en las que se nombra a alguien.

En el presente estudio, la mayoría de los futbolistas analizados tienden a responder a compañeros de profesión, bien de su mismo equipo en donde militan, bien de la selección en la que juegan e incluso de otros conjuntos rivales, aunque cabe la posibilidad de que en su momento fueran compañeros de vestuario.

Otros, por su parte, tienden a responder a deportistas de otras disciplinas por las que sienten devoción, como son el baloncesto (principalmente la NBA) o el fútbol americano. Así, por ejemplo, se da el caso de que dos de los futbolistas estudiados, Piqué y Ronaldo, responden al mismo jugador de fútbol americano, Chad Javon Johnson, más conocido como @ochocinco.

\section{Discusión}

Uno de los aspectos más interesantes de Twitter es la posibilidad de relación que se establece entre usuarios. El éxito de esta red social se basa en las conversaciones y el intercambio de información y opiniones con otras personas. Según Marwick \& Boyd (2011) o Wang \& Zhou (2015), Twitter cambia las relaciones que se establecen entre fans y celebridades. Es por ello que, teniendo en cuenta la popularidad de los futbolistas analizados, sorprende su poca actividad en la red de microblogging, lo que confirma en parte lo planteado en la H1. Alguien como Cristiano Ronaldo, por ejemplo, considerado uno de los mejores jugadores del mundo, apenas llega a los 2.000 tuits, algo que está en consonancia con otros estudios sobre la comunicación e influencia de 'celebrities' en Twitter (Fernández \& García, 2016) y que discrepa con lo manifestado por otras investigaciones (Page, 2012; Gallagher, 2015) que concluyen que los personajes famosos pasan más tiempo difundiendo sus actividades diarias a través de las redes sociales que en el ejercicio de su profesión.

Si bien pudiera entenderse que los futbolistas que más interactúan en Twitter con sus seguidores son los que tienen mayor número de fans, apenas entablan un diálogo que les haga sentir a los seguidores que son escuchados por sus ídolos. Ello puede afectar a la imagen como marca de estos futbolistas ya que no satisfacen las expectativas de parte de sus seguidores. 
Dejando al margen que resulta difícil confirmar la autoría de cada tuit (Layton, Watters, \& Dazeley, 2010), el estudio demuestra que estos cinco jugadores se dirigen fundamentalmente a otros deportistas, entre los que sobresalen otros compañeros de profesión; a empresas; a periodistas y medios de comunicación; a organizaciones solidarias; $y$, como ya se ha apuntado, en menor medida a sus seguidores.

Al hilo de esto, los deportistas con los que más interactúan son fundamentalmente futbolistas con los que han compartido vestuario o rivalidad, si bien es cierto que resulta llamativo el hecho de que entre ellos cinco apenas haya diálogo pese a que son o han sido compañeros de equipo. En este sentido, la forma de interacción más empleada es la mención y el retuit. Y, al igual que se demuestra en otras investigaciones (Blaszka, Burch, Frederick, Clavio, \& Walsh, 2012), utilizan los hashtags para participar en conversaciones con múltiples actores agrupados en torno a un mismo acontecimiento.

En el presente estudio, los futbolistas analizados emplean sus cuentas en la red de microblogging para hablar de sus clubes, de sus partidos, de sus triunfos o para publicar fotos para sus fans, entre otras cosas, lo que indica un uso de la red egocéntrico y alejado de otros usos más comunes como opinar o criticar (Weeks, Ardévol-Abreu, \& Gil de Zuñiga, 2017).

Twitter es, por tanto, empleado como una herramienta de autopromoción, de exaltación de la propia personalidad del futbolista, como parte de un proceso de 'celebrificación' (Richardson, 2015) quien se aleja de un intento por humanizar su figura, de buscar conectar con su público. Ello ratifica la $\mathrm{H} 2$

Otro aspecto a destacar es el uso de la red de microblogging para mostrar una faceta solidaria. Los perfiles de estos futbolistas se convierten también en una plataforma para apoyar diversas iniciativas de campañas impulsadas por organizaciones sin ánimo de lucro, cumpliéndose la H3.

Las empresas y/o patrocinadores han detectado que Twitter constituye un canal mucho más rentable que la radio o la televisión. De manera casi paralela, los deportistas son considerados como pequeñas empresas por parte de sus gestores, con el objetivo de conseguir una mayor rentabilidad del valor de su marca personal. Al establecer ese paralelismo deportista-empresa, la creación de una marca reconocida posibilita traducir el valor de esa marca en una generación de ingresos (Zamora, Sanahuja \& Blay, 2015: 103). En este sentido, todos los futbolistas analizados han recurrido también al hashtag para labores publicitarias, con el claro objetivo de atraer consumidores reforzando las campañas de las marcas de las que son imagen. Los 280 caracteres se convierten en una fuente de ingresos importante para estos deportistas que actúan como prescriptores y que cobran por tuits apoyando la marca, lo que respalda la $\mathrm{H} 4$.

\section{Conclusiones}

En el presente estudio se ha demostrado que los futbolistas utilizan Twitter más como herramienta de autopromoción, de creación de imagen de marca más que como un instrumento válido para establecer vínculos estrechos con sus fans. Su perfil en la red de microblogging se crea para responder a una función publicitaria y para aumentar la visibilidad de sus patrocinadores, dejando la posibilidad de dialogar con sus seguidores en un segundo plano. Pese a que esta conversación existe y se da con múltiples actores, se produce fundamentalmente entre iguales; es decir, con otros compañeros de profesión, y, en menor medida, con aquellos incondicionales que mantienen sus cuotas de popularidad. No obstante, estos futbolistas intentan matizar esta imagen tan mercantilista mostrando también una faceta solidaria que busca humanizarlos.

Esta investigación se ha encontrado con una serie de limitaciones que, en ningún caso, empañan los resultados obtenidos. Llama poderosamente la atención la ausencia significativa en este trabajo de un jugador como Leo Messi, que si bien cuenta con millones de seguidores en Facebook, Instagram e incluso en la red social china Weibo, no dispone de un perfil en Twitter. 
Igualmente, resulta difícil determinar si estos cinco jugadores analizados son los autores de los contenidos publicados o si alguno de ellos o todos ellos recurren a un perfil como el del content manager, cada vez más demandado en la estrategia de comunicación y cuyas funciones pueden ir desde el propio diseño de un plan de comunicación para el futbolista hasta la creación de sus contenidos.

Por último, este trabajo se ha centrado fundamentalmente en el análisis de los contenidos textuales, dejando de lado el estudio más en profundidad de las imágenes, vídeos y enlaces que incluyen en sus mensajes. Esto, quizás más que una limitación, pudiera considerarse una nueva línea de investigación a futuro, que contribuya a enriquecer el conocimiento de las publicaciones que realizan los futbolistas.

Asimismo, podría ser interesante también examinar los contenidos que estos deportistas suben a otras redes sociales (Facebook, Instagram, TikTok...), estableciendo una comparativa entre ellas y determinando si los usos son los mismos o las emplean para objetivos distintos.

Si se tiene en cuenta que los cinco jugadores analizados, pese a ser de nacionalidades diferente, compiten en distintas ligas europeas (española, italiana e inglesa), cabría la posibilidad de implementar a futuro tanto el número de futbolistas estudiados como su presencia en otras ligas que cuentan igualmente con un número de entusiastas elevado, como, por ejemplo, las sudamericanas (Brasil, Argentina, etc.).

\section{Bibliografía}

Adamson, G., Jones, W. y Tapp, A. (2006). From CRM to FRM: applying CRM in the football industry. The Journal of Database Marketing \& Customer Strategy Management, 13 (2), 156-172. https://doi.org/10.1057/palgrave.dbm.3240292.

Ahmed, W. y Lugovic, S. (2019). Social media analytics: analysis and visualization of news diffusion using NodeXL. Online Information Review, 43 (1), 149-160. https://doi.org/10.1108/ OIR-03-2018-0093.

Antezana, L. (2003). Fútbol: espectáculo e identidad. En Alabarces, P. (Ed). Futbologías: fútbol, identidad y violencia en América Latina. (pp. 85-98). Ed. CLACSO.

Bakshy, E., Hofman, J.M., Mason, W.A. y Watts, D.J. (2011). Everyone's an influencer: quantifying influence on twitter. En Proceedings of the fourth ACM Internacional Conference on Web Search and Data Mining 65-74. https://doi.org/10.1145/1935826.1935845. http://snap. stanford.edu/class/cs224w-readings/bakshy11influencers.pdf.

Billings, A. C., Qiao, F., Conlin, L. y Nie, T. (2017). Permanently desiring the temporary? Snapchat, social media, and the shifting motivations of sports fans. Communication \& Sport, 5 (1), 10-26. https://doi.org/10.1177/2167479515588760.

Birkner, T. y Nöelleke, D. (2016). Soccer players and their media-related behavior: A contribution on the mediatization of sports. Communication \& Sport, 4 (4), 367-384. https://doi. org/10.1177/2167479515588719.

Blaszka, M., Burch, L. M., Frederick, E. L., Clavio, G. y Walsh, P. (2012). \#WorldSeries: An empirical examination of a Twitter hashtag during a major sporting event. International Journal of Sport Communication, 5 (4), 435-453. https://doi.org/10.1123/ijsc.5.4.435.

Boehmer, J. y Tandoc, E. C. Jr. (2015). Why we retweet: Factors influencing intentions to share sport news on Twitter. International Journal of Sport Communication, 8 (2), 212-232. https://doi. org/10.1123/ijsc.2015-0011. 
Boor, S.; Bosshardt, A.; Green, M.; Hanson, Ch.; Savage, J.; Shaffer, A.; Winn, Ch. (2016). Top of the table. Football money league. https:/www2.deloitte.com/content/dam/Deloitte/uk/Documents/ sports-business-group/uk-deloitte-sport-football-money-league-2016.pdf.

Borgatti, S. P.; Mehra, A.; Brass, D. J. y Labianca, G. (2009). "Network analysis in the social sciences". Science, 323, (5916), 892-895. https://doi.org/10.1126/science.1165821

Boyle, R. (2006). Sports Journalism: Context and Issues. Sage.

Boyle, R. (2017). Sports journalism: changing journalism practice and digital media. Digital Journalism, 5 (5), 493-495. https://doi.org/10.1080/21670811.2017.1281603

Boyle R., Rowe D. y Whannel G. (2010) Delight in Trivial Controversy'? Questions for sports journalism. En Allan, S. (Ed.) The Routledge Companion to News and Journalism (pp. 245-255). Routledge.

Brison, N. T., Byon, K. K. y Baker, T. A. (2016). To tweet or not to tweet: The effects of social media endorsements on unfamiliar sport brands and athlete endorsers. Innovation, 18 (3), 309326. https://doi.org/10.1080/14479338.2016.1237304.

Browning, B. y Sanderson, J. (2012). The positives and negatives of Twitter: Exploring how student-athletes use Twitter and respond to critical tweets. International Journal of Sport Communication, 5 (4), 503-521. https://doi.org/10.1123/ijsc.5.4.503.

Calzada, E. (2012). Show me the money!Cómo conseguir dinero a través del márketing deportivo. Libros de Cabecera.

Cano Tenorio, R. (2017). Técnicas de márketing de los clubes de fútbol de élite en las redes sociales. Retos, 13 (1), 43-58. https://doi.org/10.17163/ret.n13.2017.03.

Cano Tenorio, R. y Paniagua, F.J. (2017): El uso de Twitter por parte de los futbolistas profesionales. Contenidos y relaciones con los públicos. Revista Internacional de Relaciones Públicas, 7 (13), 101-122. http://dx.doi.org/10.5783/RIRP-13-2017-07-101-122.

Castillo, A., Fernández, M.J. y Castillero, E. (2016). Fútbol y redes sociales. Análisis de la gestión de Relaciones Públicas 2.0 por los clubes de fútbol. Estudios sobre Mensaje Periodístico, 22 (1), 239-254. http://dx.doi.org/10.5209/rev_ESMP.2016.v22.n1.52592

Clavio, G. y Kian, T. M. (2010). Uses and gratifications of a retired female athlete's Twitter followers. International Journal of Sport Communication, 3 (4), 485-500. https://doi.org/10.1123/ ijsc.3.4.485.

Cleland, J. A. (2009). The Changing Organizational Structure of football clubs and their relationship with external media. International Journal of Sport Communication, 2 (4), 417-431. https://doi.org/10.1123/ijsc.2.4.417.

Cleland, J. A. (2010). From passive to active: the changing relationship between supporters and football clubs. Soccer \& Society, 11 (5), 537-552. https://doi.org/10.1080/14660970.2010.497348

Coche, R. (2017). How Athletes Frame Themselves on Social Media: An Analysis of Twitter Profiles. Journal of Sports Media, 12(1), 89-112. https://doi.org/10.1353/jsm.2017.0004

Cokley, J., Patching, R. y Scott, P. (2006) Gender preference in journalism education: Why sport misses out. Australian Journalism Review, 28 (2), 127-145. https://search.informit.com.au/ documentSummary; $\mathrm{dn}=200703672 ;$ res=IELAPA. 
Cooper, B. B. (2013). Surprising New Twitter Stats to Help You Reach More Followers. https:// buffer.com/resources/10-new-twitter-stats-twitter-statistics-to-help-you-reach-your-followers.

Del Fresno García, M., Daly, A.J. y Segado Sánchez-Cabezudo, S. (2016). Identifying the new Influences in the Internet Era: Social Media and Social Network Analysis. Revista Española de Investigaciones Sociológicas (REIS), 153 (1), 23-40. http://dx.doi.org/10.5477/cis/reis.153.23

Dolles, H. y So'derman, S. (Eds.) (2013). Handbook of Research on Sport and Business. Edward Elgar Publishing.

English, P. (2016). Mapping the sports journalism field: Bourdieu and broadsheet newsrooms. Journalism, 17 (8), 1001-1017. https://doi.org/10.1177/1464884915576728.

Fernández, C. y García-Guardia, M.L. (2016). Las principales celebrities en Twitter: análisis de su comunicación e influencia en la red social. Comun. Midia Consumo, 13 (38), 116-129. http:// dx.doi.org/10.18568/cmc.v13i38.128.

Freeman, L. C. (2004). The development of social network analysis. A study in the sociology of science, 1 (687), 159-167.

Frujak, H., Frawley, H., y Bush, S. (2017). Quantifying the value of sport broadcast rights. Media International Australia, 164 (1), 104.116. https://doi.org/10.1177/1329878X17698051.

Gallagher, M. (2015). John Berger, Paris Hilton, and The Rich Kids of Instagram: The Social and Economic Inequality of Image Sharing and Production of Power Through Self-Promotion. (Tesis doctoral), Claremont McKenna College. http://scholarship.claremont.edu/scripps_theses/545/.

Ginesta, X. (2009). Les Tecnologies de la Informació i la Comunicació i l'esport: una anàlisi de la Primera Divisió espanyola de futbol (2006-2008) (Tesis doctoral). Universitat Autònoma de Barcelona, https://ddd.uab.cat/pub/tesis/2009/tdx-0511110-140123/xgp1de1.pdf.

Ginesta, X. (2010). Los medios propios de los clubes de fútbol españoles. De la revista oficial a los canales de TDT. Estudios sobre el Mensaje Periodístico, 16, 145-166. https://revistas.ucm.es/ index.php/ESMP/article/view/ESMP1010110145A/11385.

Ginesta, X. (2011). El fútbol y el negocio del entretenimiento global. Los clubes como multinacionales del ocio. Comunicación y Sociedad, 24 (1), 141-166.

Girón Santos, M. (2015). Redes sociales y Fórmula 1. Análisis de la interactividad de los pilotos durante el campeonato mundial de 2014. Index. Comunicación, 5 (1), 123-153. https://journals. sfu.ca/indexcomunicacion/index.php/indexcomunicacion/article/view/208/179.

González, M. (2004). El reflejo del deporte en los medios de comunicación en España. Revista de Estudios Sociológicos, 4, 271-280.

Gregory, S. (2009, June 5). Twitter craze is rapidly changing the face of sports. Sports Illustrated. https://www.si.com/more-sports/2009/06/05/twitter-sports

Grimmer, C.G. y Clavio, G. (2019). Sport pro = Twitter pro? - How soccer stars use Twitter at the height of their career. International Journal of Sport Management and Marketing, 19(3-4) https:// doi.org/10.1504/IJSMM.2019.099782

Hambrick, M., Simmons, J., Greenhalgh, G. y Greenwell, Ch. (2010). Understanding Professional Athletes' Use of Twitter: A Content Analysis of Athlete Tweets. International Journal of Sport Communication, 3 (4), 454-471. https://doi.org/10.1123/ijsc.3.4.454. 
Hansen, D. L., Shneiderman, B., y Smith, M. A. (2010). Analyzing social media networks with NodeXL: Insights from a connected world. Morgan Kaufmann

Helland, K. (2007). Changing Sports, Changing Media. Mass Appeal, the Sports/Media Complex and TV Sports Rights. Nordicom Review, 28, 105-119.

Hernández, A., Osorio, J. y Zapata, D. (2013). Periodismo deportivo. Entre líneas, voces e imágenes. Imprenta Departamental de Antioquía.

Herrero, J. y Romero, H. (2015). Investigar la comunicación deportiva: una disciplina en auge académico. Fonseca, Journal of Communication, 10, 7-8.

Highfield, T., Harrington, S. y Bruns, A. (2013). Twitter as a technology for audiencing and fandom: The\# Eurovision phenomenon. Information, Communication \& Society, 16 (3), 315-339. https://doi.org/10.1080/1369118X.2012.756053.

Hopwood, M. (2010). Public Relations and the Media. En Hamil, S.; Chadwick, S. (Eds.). Managing Football. An international perspective (pp. 55-57). Butterworth-Heinemann.

Hull, K. (2014). A hole in one (hundred forty characters): A case study examining PGA tour golfers' Twitter use during the masters. International Journal of Sport Communication, 7, 245260. https://doi.org/10.1123/IJSC.2013-0130.

Hutchins, B. (2011) The acceleration of media sport culture. Twitter, telepresence and online messaging. Information, Communication \& Society, 14 (2), 237-257. https://doi.org/10.1080/1369 $118 X .2010 .508534$.

Hutchins, B. (2014). Sport on the Move: The Unfolding Impact of Mobile Communications on the Media Sport Content Economy. Journal of Sport and Social Issues, 38 (6), 509-527. https://doi. org/10.1177/0193723512458933.

Hutchins, B. y Rowe, D. (2009). From broadcast scarcity to digital plenitude: The changing dynamics of the media sport content economy. Television \& New Media, 10(4), 354-370. https:// doi.org/10.1177/1527476409334016.

Kase, K., De Hoyos, I. U., Sánchis, C. M. y Bretón, M. O. (2007). The proto-image of Real Madrid: Implications for Marketing and Management. International Journal of Sports Marketing and Sponsorship, 8 (3), 212-233. https://doi.org/10.1108/IJSMS-08-03-2007-B004.

Kim, J., y Song, H. (2016). Celebrity's self-disclosure on Twitter and parasocial relationships. A mediating role of social presence. Computers in Human Behavior, 62, 570-577. https://doi. org/10.1016/j.chb.2016.03.083.

Lardo, A., Dumay, J., Trequattrini, R., y Russo, G. (2017). Social media networks as drivers for intellectual capital disclosure: Evidence from professional football clubs. Journal of Intellectual Capital, 18 (1), 63-80. https://doi.org/10.1108/JIC-09-2016-0093.

Lastra, G. (2014). El periodismo deportivo en Twitter: análisis del uso de la herramienta por parte de los profesionales de la información (Tesis Doctoral). Universidad Europea. https://abacus.universidadeuropea.es/bitstream/handle/11268/3805/GLP_Tesis. pdf? sequence $=1 \&$ isAllowed $=y$.

Layton, R., Watters, P. y Dazeley, R. (2010). Authorship Attribution for Twitter in 140 Characters or Less. En Proceedings of the 2010 Second Cybercrime and Trustworthy Computing Workshop, 1-8. https://doi.org/10.1109/CTC.2010.17. https://ieeexplore.ieee.org/xpl/conhome/5613989/proceeding. 
Lebel, K. y Danylchuk, K. (2014). An Audience Interpretation of Professional Athlete SelfPresentation on Twitter. Journal of Applied Sport Management, 6 (2). https://js.sagamorepub.com/ jasm/article/view/4047.

Ledingham, J. A. (2003). Explicating relationship management as a general theory of public relations. Journal of Public Relations Research, 15 (2), 181-198. https://doi.org/10.1207/ S1532754XJPRR1502_4.

Lee, E. y Shin, S. (2012). Are They Talking to Me? Cognitive and Affective Effects of Interactivity in Politicians' Twitter Communication. Cyberpsychology, Behavior, and Social Networking, 15 (10), 515-520. https://doi.org/10.1089/cyber.2012.0228.

Lobillo, G. y Muñoz, A. D. (2016). El papel de las redes sociales en las estrategias de expansión de mercado en los clubes de fútbol españoles. El uso personalizado de Twitter en lengua árabe del Real Madrid CF y FC Barcelona. Trípodos, 38, 195-214.

Lovejoy, K., Waters, R. D., y Saxton, G. D. (2012). Engaging stakeholders through Twitter: how nonprofit organizations are getting more out of 140 characters or less. Public Relations Review, 38 (2), 313-318. https://doi.org/10.1016/j.pubrev.2012.01.005.

Marshall, P.D. (2010). The promotion and presentation of the self: celebrity as marker of presentational media. Celebrity Studies, 1 (1), 35-48. https://doi.org/10.1080/19392390903519057.

Marwick, A.F. y Boyd, D. (2011). To See and Be Seen: Celebrity Practice on Twitter. Convergence: The International Journal of Research into New Media Technologies, 17, 139-158. https://doi.org/10.1177/1354856510394539.

McCarthy, J., Rowley, J., Jane, C. y Pioch, E. (2014). Managing brand presence through social media: the case of UK football clubs. Internet Research, 24 (2), 181-204. https://doi.org/10.1108/ IntR-08-2012-0154.

Miller, T. (2001). Globalization and sport: Playing the world. Sage.

Moragas Spà, M. (1999). Comunicación y deporte en la era digital: sinergías, contradicciones y responsabilidades educativas. Contratexto, 12, 73-92. http://olympicstudies.uab.es/pdf/wp107_ spa.pdf.

Naraine, M. L., Pegoraro, A., \& Wear, H. (2021). \#WeTheNorth: Examining an Online Brand Community Through a Professional Sport Organization's Hashtag Marketing Campaign. Communication \& Sport, 9 (4), 625-645. https://doi.org/10.1177/2167479519878676.

Nicholson, M., Zion, L. y Lowden, D. (2011). A profile of Australian sports journalists (revisited). Media International Australia, 140, 84-96. https://doi.org/10.1177/1329878X1114000112.

O’Hallarn, B., Shapiro, S. L., Wittkower, D. E., Ridinger, L. y Hambrick, M. E. (2019). A model for the generation of public sphere-like activity in sport-themed Twitter hashtags. Sport Management Review, 22 (3), 407-418. https://doi.org/10.1016/j.smr.2018.06.001.

Olabe, F. (2009). La comunicación no convencional en los clubes de fútbol. Pensar la publicidad, 3 (1), 121-137. https://revistas.ucm.es/index.php/PEPU/article/view/PEPU0909120121A/15348.

Olabe, F. (2016). El periodismo deportivo condicionado por la gestión comunicativa de los clubes de fútbol: el caso del FC Barcelona. Estudios sobre el Mensaje Periodístico, 22 (1), 463-481. http://dx.doi.org/10.5209/rev_ESMP.2016.v22.n1.52607. 
Page, R. (2012). The linguistics of self-branding and micro-celebrity in Twitter: The role of hashtags. Discourse \& Communication, 6 (2), 181-201. https://doi.org/10.1177/1750481312437441.

Pegoraro, A. (2010). Look who's talking-athletes on Twitter: A case study. International Journal of Sport Communication, 3 (4), 501-514. https://doi.org/10.1123/ijsc.3.4.501.

Pegoraro, A. y Jinnah, N. (2012). Tweet'em and reap'em: The impact of professional athletes' use of Twitter on current and potential sponsorship opportunities. Journal of Brand Strategy, 1 (1), 85-97.

Pérez Dasilva, J., Meso Ayerdi, K. y Mendiguren Galdospín, T. (2018). Do Spanish political leaders interact with the media and journalists via Twitter?. Communication \& Society. 31 (3), 299-317. https://doi.org/10.15581/003.31.3.299-317.

Pérez Dasilva, J., Santos Diez, M. T. y Meso Ayerdi, K. (2021). Las asociaciones de enfermedades raras: Estructura de sus redes e identificación de los líderes de opinión mediante la técnica del análisis de redes sociales. Revista Latina De Comunicación Social, 79, 175-205. https://doi. org/10.4185/RLCS-2021-1498

Pieper, L. P. (2013). It's a whole new ball-game: How social media is changing sports. Journal of Sport Management, 27 (3), 261-262. https://doi.org/10.1123/jsm.27.3.261.

Post, J., Preston, L. y Sachs, S. (2002). Managing the extended enterprise: the new stakeholder view. California Management Review, 45 (1), 6-28. https://doi.org/10.2307/41166151.

Price, J., Farrington, N. y Hall, L. (2013). Changing the game? The impact of Twitter on relationships between football clubs, supporters and the sports media. Soccer \& Society, 14 (4), 446-461. https://doi.org/10.1080/14660970.2013.810431.

Prudkin, G. (2010). Blogosfera, midiasfera y fútbol: aspectos del funcionamiento de un nuevo ecosistema informativo en la Argentina. Prisma.com, 9. http://ojs.letras.up.pt/index.php/ prismacom/article/view/2052/3096.

Reed, S. (2013). American sports writers' social media use and its influence on professionalism. Journalism Practice, 7 (5), 555-571. https://doi.org/10.1080/17512786.2012.739325.

Richardson, K. (2015). Celebrity politics. En Gianprieto, M. (Ed.) International Encyclopedia of Political Communication (pp. 41-44). Wiley-Blackwell.

Rojas Torrijos, J.L. (2014). Periodismo deportivo. Nuevas tendencias y perspectivas de futuro. Correspondencias \& Análisis, 4, 177-190. https://doi.org/10.24265/cian.2014.n4.09.

Rojas Torrijos, J.L. (2018). La estrategia digital de digitalización de Marca en Latinoamérica. Estudio de caso de Marca Claro en México. Revista de Comunicación, 17 (1), 133-154. https:// doi.org/10.26441/RC17.1-2018-A7.

Rosen, S. (1981). The economics of superstars. The American Economic Review, 71 (5), 845-858. http://www.jstor.org/stable/1803469.

Rowe, D. (1996). The global love-match: sport and television. Media, Culture \& Society, 18 (4), 565-583. https://doi.org/10.1177/016344396018004004.

Rowe, D. (2003). Sport, Culture \& Media. McGraw-Hill Education.

Rowe, D. (2004). Sport, Culture and the Media: The Unruly Trinity. Open University Press. 
Rowe, D. (2013). Reflections on Communication and Sport. On Nation and Globalization. Communication \& Sport, 1 (1-2), 18-29. https://doi.org/10.1177/2167479512467328.

Salinero, J.C. (2014). Nuevas formas de comunicación en el deporte. El twitter de Cristiano Ronaldo. (Trabajo Fin de Grado). Universidad de Valladolid. https://uvadoc.uva.es/ handle/10324/6252

Sanahuja Peris, G. (2012). Análisis de los procesos en la comunicación corporativa de los clubes deportivos profesionales españoles. Estudio exploratorio. adComunica, 3, 171-189. http://dx.doi. org/10.6035/2174-0992.2012.3.11.

Sanderson, J. (2008). The blog is serving its purpose: Self-presentation strategies on 38pitches. com. Journal of Computer-Mediated Communication, 13, (4), 912-936. https://doi.org/10.1111/ j.1083-6101.2008.00424.x.

Sanderson, J. (2011). How social media is changing sports: It's a whole new ballgame. Hampton Press.

Sanderson, J. (2013). Stepping into the (social media) game: Building athlete identity via Twitter. En Luppicini, R. (Ed.). Handbook of Research on Technoself: Identity in a Technological Society (pp. 419-438). IGI Global.

Sanderson, J. y Kassing, J. W. (2011). Tweets and blogs: Transformative, adversarial, and integrative developments in sports media. En A. C. Billings (Ed.). Sports Media: Transformation, Integration, Consumption (pp. 114-127). Routledge.

Schultz Jørgensen, S. (2005). The world's best advertising agency: The sports press. International Sports Press Survey. https://www.playthegame.org/upload/Sport_Press_Survey_English.pdf.

Schultz, B. y Sheffer, M.L. (2010). An exploratory study of how Twitter is affecting sports journalism. International Journal of Sport Communication, 3 (2), 226-239. https://doi. org/10.1123/ijsc.3.2.226.

Shareef, F. y Davey, H. (2005). Accounting for intellectual capital: Evidence from listed English football clubs. Journal of Applied Accounting Research, 7 (3), 78-116. https://doi. org/10.1108/96754260580001042.

Sellitto, C. (2014). An analysis of social media policies adopted by sporting organisations. International Journal of Sport \& Society, 4 (2), 13-24.

Small, T. A. (2011). What the hashtag? A content analysis of Canadian politics on Twitter. Information, Communication \& Society, 14 (6), 872-895. https://doi. org/10.1080/1369118X.2011.554572.

Sotelo, J. (2012). Deporte y social media: el caso de la Primera División del fútbol español. Historia y Comunicación Social, 17, 217-230. http://dx.doi.org/10.5209/rev_HICS.2012. v17.40607.

Thrassou, A.; Vrontis, D., y Kartakoullis, N. (2012). Contemporary Marketing Communications frameworks for Football Clubs. Journal of Promotion Management, 18 (3), 278-305. https://doi.or $\mathrm{g} / 10.1080 / 10496491.2012 .696454$.

Vale, L., \& Fernandes, T. (2018). Social media and sports: driving fan engagement with football clubs on Facebook. Journal of Strategic Marketing, 26 (1), 37-55. https://doi.org/10.1080/096525 4X.2017.1359655 
Wang, X. (2013). Applying the integrative model of behavioral prediction and attitude functions in the context of social media use while viewing mediated sports. Computers in Human Behavior, 29 (4), 1538-1545. https://doi.org/10.1016/j.chb.2013.01.031.

Wang, Y. y Zhou, S. (2015). How Do Sports Organizations Use Social Media to Build Relationships? A Content Analysis of NBA Clubs' Twitter Use. International Journal of Sport Communication, 8 (2), 133-148. https://doi.org/10.1123/ijsc.2014-0083.

Weeks, B. E., Ardévol-Abreu, A., y Gil de Zúñiga, H. (2017). Online influence? Social media use, opinión leadership and political persuasion. International Journal of Public Opinion Research, 29 (2), 214-239. https://doi.org/10.1093/ijpor/edv050.

Yan, G., Watanabe, N. M., Shapiro, S. L., Naraine, M. L., \& Hull, K. (2019). Unfolding the Twitter scene of the 2017 UEFA Champions League Final: social media networks and power dynamics. European Sport Management Quarterly, 19 (4), 419-436. https://doi.org/10.1080/1618 4742.2018.1517272.

Zamora, J., Sanahuja, G. y Blay, R. (2015). El gestor de marca personal en el ámbito deportivo. Questiones Publicitarias, 1 (20), 101-116. https://doi.org/10.5565/rev/qp.11.

Zimmerman, M., Johnson, J., y Ridley, M. (2016). Twitter Use by College Football Coaches: An Examination of the Football Bowl Subdivision. Journal of Contemporary Athletics, 10 (1), 33-50. 